\title{
Medial Longitudinal Arch: Accuracy, Reliability, and Correlation Between Navicular Drop Test and Footprint Parameters
}

\author{
Juan Carlos Zuil-Escobar, PhD, ${ }^{a}$ Carmen Belén Martínez-Cepa, PhD, ${ }^{a}$ \\ Jose Antonio Martín-Urrialde, $\mathrm{PhD},{ }^{\mathrm{a}}$ and Antonia Gómez-Conesa, $\mathrm{PhD}{ }^{\mathrm{b}}$
}

\begin{abstract}
Objective: The purpose of this study was to evaluate the correlation among the navicular drop test, the arch angle, the Staheli index and the Chippaux-Smirak index. The reliability and the correlation among the footprint parameters were also estimated. Methods: A cross-sectional study ( $\mathrm{n}=86 ; 59.3 \%$ women; 27.8 years, standard deviation: 4.8 years) was carried out. The navicular drop test was evaluated and footprint parameters using a plantar pressure platform were recorded in the dominant foot. Pearson correlation coefficients, intraclass correlation coefficient, standard error of measurement, and minimum detectable change were calculated.

Results: Both intrarater and interrater reliability were excellent for all the parameters evaluated (intraclass correlation coefficients $>0.880$ ). Statistically significant correlations existed between the navicular drop test and footprints parameters (arch angle $=0,643$; Staheli index $=0.633$; Chippaux-Smirak index $=0.614$ ). The footprint parameters had excellent correlation with each other (0.838-0.881). The navicular drop test and the footprint parameters studied were reproducible and thus had excellent reliability.

Conclusion: The correlations obtained between the navicular drop test and the footprint parameters evaluated were good. The navicular drop test appears to be a reproducible, valid, and simple test for evaluating medial longitudinal arch height, having fewer disadvantages than using footprint parameters. (J Manipulative Physiol Ther 2018;41:672-679)

Key indexing terms: Data Accuracy; Foot; Reproducibility of Results
\end{abstract}

\section{INTRODUCTION}

The medial longitudinal arch (MLA) of the foot is related to shock absorption and force transmission in the standing position and during the gait. ${ }^{1}$ The MLA is a variable structure, ${ }^{2}$ and changes in its height can modify plantar pressure distributions ${ }^{3}$ and affect force absorption, ${ }^{4}$ muscular activity, ${ }^{5-7}$ stability, ${ }^{8}$ and gait. ${ }^{9,10}$ In addition, several modifications in the lower extremity alignments, including subtalar pronation, ${ }^{11}$ tibial internal rotation, ${ }^{12}$ genu recurvatum, ${ }^{13}$ and anterior knee laxity, ${ }^{14,15}$ are related to a

\footnotetext{
${ }^{a}$ Physical Therapy Department, San Pablo CEU University, Madrid, Spain.

${ }^{\mathrm{b}}$ Physical Therapy Department, Murcia University, Murcia, Spain.

Corresponding author: Carmen Belén Martínez-Cepa, PhD, Avda De Montepríncipe s/n, 28668, Boadilla del Monte, Spain. Tel.: +34 913724700. (e-mail: cmcepa@ceu.es).

Paper submitted November 30, 2017; in revised form April 3, 2018; accepted April 5, 2018.

0161-4754

Copyright (C) 2018 by National University of Health Sciences. https://doi.org/10.1016/j.jmpt.2018.04.001
}

lower MLA. In the other hand, a higher MLA is associated with a subtalar supination ${ }^{11}$ and a varus hindfoot. ${ }^{16}$

Changes in the height of the MLA can increase the risk of lower limb injuries, ${ }^{17}$ including foot pain, ${ }^{2}$ toe deformities, ${ }^{18}$ ankle injuries, ${ }^{19}$ tibial stress syndrome, ${ }^{20,21}$ knee osteoarthritis, ${ }^{22}$ iliotibial band syndrome, ${ }^{19}$ patellofemoral syndrome, ${ }^{23}$ and noncontact cruciate anterior ligament injuries. ${ }^{24,25}$ These relationships can be important in sports. Thus the evaluation of the MLA is important both in clinical practice and in research.

There are many different methods to evaluate MLA height, including visual observation, radiographs, footprints, and clinical measurements. ${ }^{26}$ Visual observation depends on the subjectivity of the rater. ${ }^{27}$ Radiographs present several disadvantages, including ionizing radiation exposure and cost accessibility. ${ }^{28}$ Footprints parameters, including the arch index (AI), ${ }^{29}$ Staheli index (SI), ${ }^{30}$ Chippaux-Smirak index (CSI), ${ }^{17}$ and arch angle (AA), ${ }^{17}$ can be obtained by ink or digital systems. Although ink footprints are noninvasive and inexpensive, they present several limitations, such as difficulties in interpretation and the inaccuracy of measurements. ${ }^{31}$ Digital systems have lesser limitations, but they are expensive. 
Clinical techniques are simple and have no side effects. These techniques include the study of navicular position because this is considered a support structure for the MLA. ${ }^{11}$ The navicular drop test (NDT), described by Brody ${ }^{32}$ in 1982, is one of the clinical tests most commonly used to study MLA. ${ }^{13,33}$ It identifies the difference (in millimeters) between navicular tuberosity height in the subtalar joint in a neutral position and subtalar joint relaxed posture. ${ }^{32}$ High NDT values are associated with subtalar pronation and lower MLA, and low NDT values are associated with subtalar supination and high MLA. ${ }^{32}$

The correlation between the NDT and the AI was evaluated, identifying small correlations in bipedal $(r=$ $0.317)$ and single leg stance $(r=0.320)^{34}$ and moderate correlation for the static $\mathrm{AI}(r=0.44)$ and the dynamic $\mathrm{AI}(r=$ 0.570). ${ }^{35}$ The $\mathrm{AI}$ is a measurement dependent on the contact area of the foot. There are other measurements not dependent on the contact area and commonly used in the clinical practice, like the AA, SI, and CSI. However, the correlations between these footprint parameters and the NDT were not previously evaluated. The aim of this study was to evaluate the correlation between the NDT and the AA, SI, and CSI. The correlation among the footprints parameters and the reliability of the NDT, AA, SI, and CSI were also estimated.

\section{Methods}

\section{Participants}

University student volunteers were recruited for this research. Participants were informed about the aims and the procedure of the study and completed a consent form. The principles outlined in the Declaration of Helsinki of 1975, revised in 2013, were followed and the research was approved by de Research Ethics Committee of the Centro de Estudios Universitarios San Pablo University. The following exclusion criteria were established: history of acute injuries in lower limbs, history of lower limb surgery, presented with lower limbs deformities, and body mass index $(\mathrm{BMI}) \geq 30$. The dominant foot $^{36}$ was evaluated in each participant. Demographic variables, including age, sex, height, weight, and BMI, were collected.

To calculate the sample size required, the G*Power program (an $\alpha$ level of .05 and $80 \%$ of statistical power) and the data from the first 20 participants were used. The lowest correlation between the NDT and the footprints parameters obtained in these participants $(r=0.633)$ and the correlation obtained by Nakhaee et $\mathrm{al}^{35}$ between the NDT and the AI (0.44) were used. The sample size required was 86 participants. Table 1 shows demographic variables.

The intrarater and interrater reliability of the NDT and footprints parameters were estimated in the first 20 participants by 2 physiotherapists with more than 6 years of experience in the use of the techniques. The NDT and the footprints parameters were collected 3 times in each session, with an interval of 48 hours between sessions. Participants and testers were blinded to the reliability results.
Table I. Means and Standard Deviations of Age, Height, Weight, and Body Mass Index

\begin{tabular}{lcc}
\hline Demographic Variables & Mean & Standard Deviation \\
\hline Age & $27.8(\mathrm{y})$ & $4.8(\mathrm{y})$ \\
Height & $168.5(\mathrm{~cm})$ & $11(\mathrm{~cm})$ \\
Weight & $66.5(\mathrm{~kg})$ & $13.6(\mathrm{~kg})$ \\
Body mass index & $23.2\left(\mathrm{~kg} / \mathrm{m}^{2}\right)$ & $2.5\left(\mathrm{~kg} / \mathrm{m}^{2}\right)$ \\
\hline
\end{tabular}

\section{Procedure}

The NDT was evaluated using a modification of the Brody ${ }^{32}$ process: With the participants standing barefoot on the floor, the tester marked the navicular tuberosity with a washable marker. The lateral and medial aspect of the talar dome of the foot was palpated with the thumb over the sinus talus and the index over the anteromedial portion of the talar dome. The foot was slowly inverted and everted until the talus was in a central position and the depressions felt under both fingers were equal. With the subtalar joint in neutral position, the distance between the navicular tuberosity and the floor was measured, in millimeters, with a ruler. The same process was repeated in non-weightbearing stance, measuring again the height of the navicular tuberosity. The NDT was the difference in the navicular tuberosity height between both measurements. The procedure was repeated 3 times in each participant.

Footprints were collected using a plantar pressure platform with a sample frequency of $30 \mathrm{~Hz}$ (Footchecker; LorAn Engineering; Bologna, Italy) placed on a firm surface. To collect footprints, participants were stood on the plantar pressure platform, with their arms relaxed by their sides, and were asked to look at a reference point located 1.8 meters from the floor ( 3 meters in front of them). The participants had to hold the bipedal stance for 15 seconds. The trials were repeated if the participants lost their balance. Three parameters were calculated (Footchecker 4.0): the AA, SI, and CSI (Fig 1). The AA is the angle between the medial line of the footprint and the line connecting the most medial aspect of the metatarsus and the most lateral point of the medial foot. ${ }^{17}$ The SI is obtained by dividing the minimal distance of the midfoot by the widest section of the rearfoot region, ${ }^{30}$ and the CSI is the ratio of the minimal distance of the midfoot to the maximal distance of the forefoot. ${ }^{17}$ The procedure was repeated 3 times in each participants. In the correlation study, the measures were collected by a physiotherapist with more than 6 years' experience in the use of the techniques.

\section{Statistical Analysis}

The normal distribution of the quantitative variables was assessed using the Kolmogorov-Smirnov test. Descriptive analysis was conducted using means and standard deviations (SDs). The reliability the NDT and of the footprints parameters was estimated using the intraclass correlation 


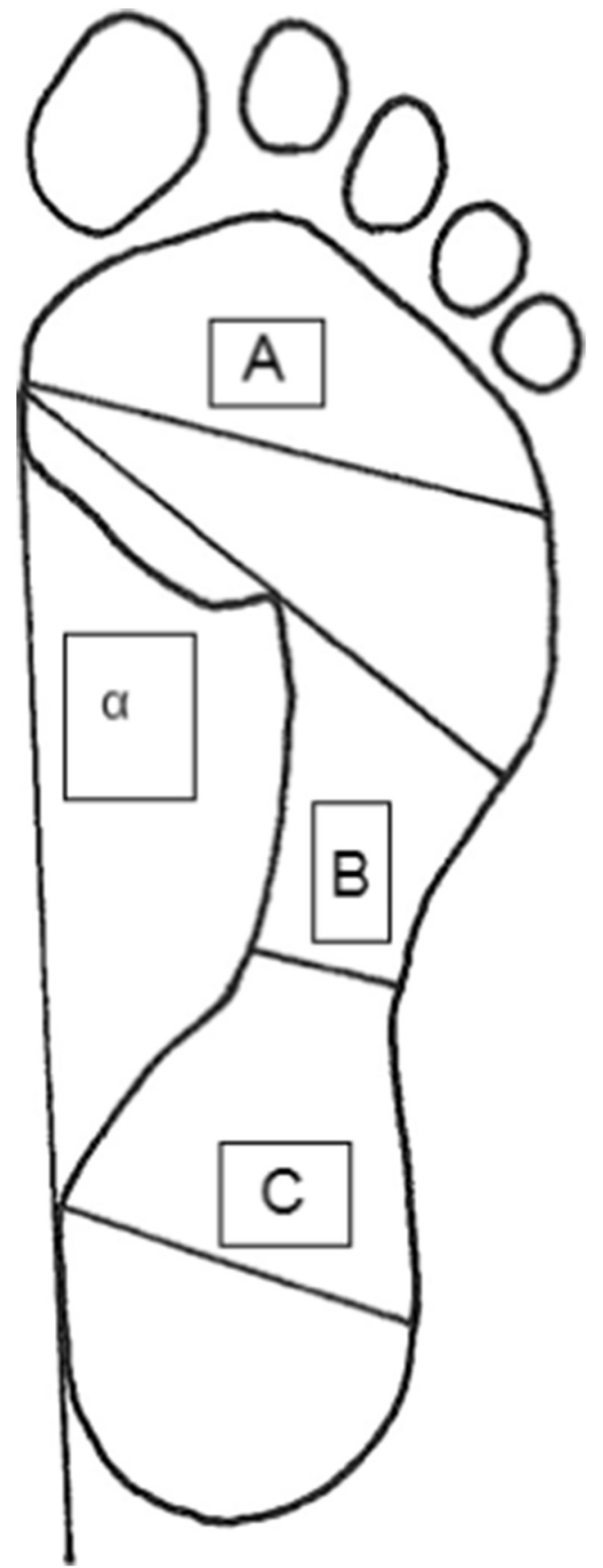

Fig I. Representative illustration of the arch angle ( $\alpha)$, the Staheli index $(B / C)$, and Chippaux-Smirak index calculation (B/A).

coefficient $\left(\mathrm{ICC}_{(3, \mathrm{k})}\right)$. The standard error of measurement (SEM) and the minimum detectable change were also calculated. The correlations were studied using the Pearson correlation coefficients $(r), 95 \%$ confidence intervals, and coefficients of determination $\left(r^{2}\right)$. The average value for each test for each participant was used. Reliability was interpreted as poor $(0-0.39)$, moderate $(0.4-0.74)$, or excellent $(\geq 0.75) .{ }^{37}$ Correlations were interpreted as poor (0-0.39), fair (0.4-0.59), good (0.6-0.74), or excellent $(\geq 0.75) .{ }^{38}$ Statistical analysis was conducted using SPSS Statistics Version 20.0 (IBM Corp, Armonk, New York), and the results were considered statistically significant at $P<.05$.

RESULTS

\section{Reliability}

Eleven women (55\%) and 9 men (45\%) were included in the reliability study. The NDT, AA, CSI, and SI had a normal distribution in the Kolmogorov-Smirnov test $(P>.05)$. Both intrarater and interrater reliability were excellent in all parameters evaluated, with ICC values $>0.880$. Table 2 shows the ICC, $95 \%$ confidence interval, SEM, and minimum detectable change for the MLA parameters intrarater and interrater reliability.

\section{Correlations}

A total of 51 women (59.3\%) and 35 men (40.7\%) were included in the study (age $=27.8$ years, $\mathrm{SD}=4.8$ years). The MLA measures had a normal distribution in the Kolmogorov-Smirnov test $(P>.05)$. The mean was $6.7 \mathrm{~mm}$ $(\mathrm{SD}=2.9)$ for the NDT, $44.4^{\circ}\left(\mathrm{SD}=7.4^{\circ}\right)$ for the $\mathrm{AA}, 46.1$ for the SI $(\mathrm{SD}=7.4)$, and 29.9 for the CSI $(\mathrm{SD}=6.3)$. Statistically significant $(P<.001)$ correlations existed between the NDT and the footprints parameters studied, with the absolute values ranging from 0.614 to 0.643 . The highest correlation was found between the NDT and the AA. Although good correlation was identified, coefficients of determination ranged from 0.377 to 0.414 . Footprints parameters had excellent correlation with each other $(r=0.838-0.881)$. The Pearson correlation coefficients, $95 \%$ confidence intervals, and coefficients of determination for all MLA parameters collected are shown in Table 3 and Figures 2, 3, and 4.

\section{DISCUSSION}

The evaluation of the MLA is necessary in clinical practice and research to obtain information related to potential mechanism of injures and also for diagnosis and treatment purposes. The NDT and the footprint parameters are techniques commonly used in clinical practice. There are no previous studies in which the correlation between the NDT and footprint parameters that are not dependent on the contact area of the foot has been evaluated.

\section{Reliability}

First of all, we evaluated the reliability of the MLA parameters collected in 20 participants. The NDT had excellent reliability, both intrarater and interrater, with ICC values ranging from 0.914 to 0.945 , and had SEM values of $<1 \mathrm{~mm}$. Regarding the intrarater reliability, rater 1 obtained a higher ICC (0.945) than rater 2 (0.922). Several authors have reported 
Table 2. Intraclass Correlation Coefficient, $95 \%$ Confidence Interval, Standard Error of Measurement and Minimum Detectable Change of Navicular Drop Test, Arch Angle, Staheli Index and Chippaux-Smirak Index

\begin{tabular}{llllll}
\hline \multicolumn{2}{l}{$\begin{array}{l}\text { NDT and } \\
\text { Footprints } \\
\text { Parameters }\end{array}$} & ICC & $95 \%$ CI & SEM & MDC \\
\hline \multicolumn{2}{l}{ Intrarater reliability } & & & & \\
NDT & Rater 1 & 0.945 & $0.898-0.970$ & 0.63 & 1.746 \\
& Rater 2 & 0.922 & $0.857-0.958$ & 0.781 & 2.165 \\
& Rater 1 & 0.941 & $0.879-0.971$ & 1.487 & 4.122 \\
AA & Rater 2 & 0.939 & $0.853-0.975$ & 1.595 & 4.421 \\
& Rater 1 & 0.969 & $0.924-0.988$ & 1.410 & 3.908 \\
SI & Rater 2 & 0.964 & $0.925-0.982$ & 1.582 & 4.385 \\
& Rater 1 & 0.976 & $0.940-0.990$ & 1.135 & 3.146 \\
CSI & Rater 2 & 0.957 & $0.912-0.979$ & 1.565 & 4.338
\end{tabular}

Interrater reliability

\begin{tabular}{llllll} 
& & ICC & $95 \%$ CI & SEM & MDC \\
NDT & Time 1 & 0.914 & $0.844-0.954$ & 0.821 & 2.276 \\
& Time 2 & 0.939 & $0.888-0.967$ & 0.642 & 1.780 \\
AA & Time 1 & 0.884 & $0.708-0.954$ & 2.342 & 6.492 \\
& Time 2 & 0.899 & $0.763-0.959$ & 2.139 & 5.929 \\
SI & Time 1 & 0.910 & $0.829-0.952$ & 2.586 & 7.168 \\
& Time 2 & 0.912 & $0.834-0.954$ & 2.507 & 6.949 \\
& & & & & \\
CSI & Time 1 & 0.920 & $0.848-0.958$ & 2.221 & 6.157 \\
& Time 2 & 0.936 & $0.845-0.974$ & 1.926 & 5.339 \\
\hline
\end{tabular}

$A A$, arch angle; $C I$, confidence interval; CSI, Chippaux-Smirak index; $I C C$, intraclass correlation coefficient; $M D C$, minimum detectable change; $N D T$, navicular drop test; $S D$, standard deviation; $S E M$, standard error of measurement; SI, Staheli index.

$P$ values for ICC $<.01$.

excellent intrarater reliability in both healthy ${ }^{23,32,39,40}$ and injured participants. ${ }^{23,41}$ The NDT interrater reliability obtained in this research was also excellent, with lower ICC values than intrarater reliability: 0.914 for time 1 and 0.939 for time 2. Several authors also reported excellent interrater reliability. ${ }^{23,41,42}$ The NDT reliability is related to the training level of the rater, with lower reliability in the case of inexperienced tester. ${ }^{42-44}$ Experience is necessary to place the subtalar joint in a neutral position ${ }^{44,45}$ and to locate the navicular tuberosity. ${ }^{46}$ The raters in our research were physiotherapists trained in the management of the NDT.
The SEM obtained in our study was $<1 \mathrm{~mm}$ for both intrarater and interrater reliability. These values are lower than the SEM obtained by other authors ${ }^{39,47,48}$ but similar to the results reported by Shultz et al. ${ }^{42}$ According to the findings of our study and the literature reviewed, the NDT was a reproducible test and had high reliability.

The footprint parameters studied also had excellent reliability, both intrarater and interrater. Intraclass correlation coefficient values for the SI and the CSI were $>0.9$. Although the SI and the CSI are commonly used in research and in clinical practice, not many studies have evaluated the reliability of these parameters in static conditions. Queen et $\mathrm{al}^{17}$ reported both intra- and interrater reliability $>0.96$ for both parameters, whereas Papuga and Burke ${ }^{49}$ obtained ICCs $>0.880$. The SI and the CSI, according to our results and the literature reviewed, had a high degree of repeatability. In our study the AA had an ICC intrarater $>0.930$ and an ICC interrater $>0.880$. Previous studies reported controversial results. Papuga and Burke ${ }^{49}$ obtained excellent intrarater reliability (ICCs $=0.817-0.993$ ). In contrast, Queen et $\mathrm{al}^{17}$ reported moderate intrarater reliability $($ ICC $=0.677)$. These authors suggested that the intrarater reliability correlation could in fact be related to the time between time measurements. Queen et al ${ }^{17}$ reevaluated participants after 7 and 10 days. In the present study, measurements were repeated after 48 hours. Regarding interrater reliability, Papuga and Burke ${ }^{49}$ obtained an ICC of 0.605 , whereas Queen et $\mathrm{al}^{17}$ reported excellent interrater reliability (ICCs $=0.807$ ). It is assumed that lesser reliability of the AA could be due to inherent variations in identifying footprint landmarks and the beginning of the midfoot and the end of the forefoot. ${ }^{49}$ The SEM of all the footprint parameters tested was low.

\section{Correlations}

The correlation between the NDT and the footprints parameters collected was significant $(P<.05)$, with $r$ values ranging from 0.614 to 0.643 . The $\mathrm{AA}$ had the highest correlation $(r=-0.643)$, followed by the SI $(r=0.633)$ and the CSI $(r=0.614)$. Although significant correlation was found, it can explain only $37.7 \%$ to $41.4 \%$ of the variance of the NDT. There are no previous studies in which the correlation between the NDT and the AA, SI, and the CSI has been evaluated, so this study is the first to do this. The relationship between the NDT and other footprint parameters was previously evaluated. Billis et $\mathrm{al}^{34}$ reported moderate correlation between the NDT and the valgus index for both single leg stance $(r=0.613)$ and bipedal stance $(r=0.657)$. These results are similar to our findings. However, the correlation between the NDT and the AI was poor $(r=0.317-0.320)^{34}$ to fair $(r=0.44-0.57) .{ }^{35}$ Although the $\mathrm{AI}$ is a measurement depending on the contact area, the footprint parameters used in our study and the valgus index are related to the width of the foot. In addition, it was reported that the $\mathrm{AI}$ is related to the BMI. ${ }^{50,51}$

Other studies have previously evaluated the correlation between the AA, SI, and CSI and the navicular. Hawes et $\mathrm{al}^{52}$ 
Table 3. Pearson Correlations and $95 \%$ Confidence Intervals

\begin{tabular}{lllll}
\hline & AA & SI & CSI & - \\
\hline AA & 1 & - & - & NDT \\
SI & $-0.838(-0.761$ to 0.892$)$ & 1 & 1 & - \\
CSI & $-0.876(-0.816$ to 0.918$)$ & $0.881(0.823-0.921)$ & $0.614(0.462-0.731)$ & - \\
NDT & $-0.643(-0.499$ to 0.752$)$ & $0.633(0.486-0.745)$ & 1 \\
\hline
\end{tabular}

$A A$, arch angle; $C S I$, Chippaux-Smirak index; $N D T$, navicular drop test; SI, Staheli index.

$P$ values for $r<0.05$.

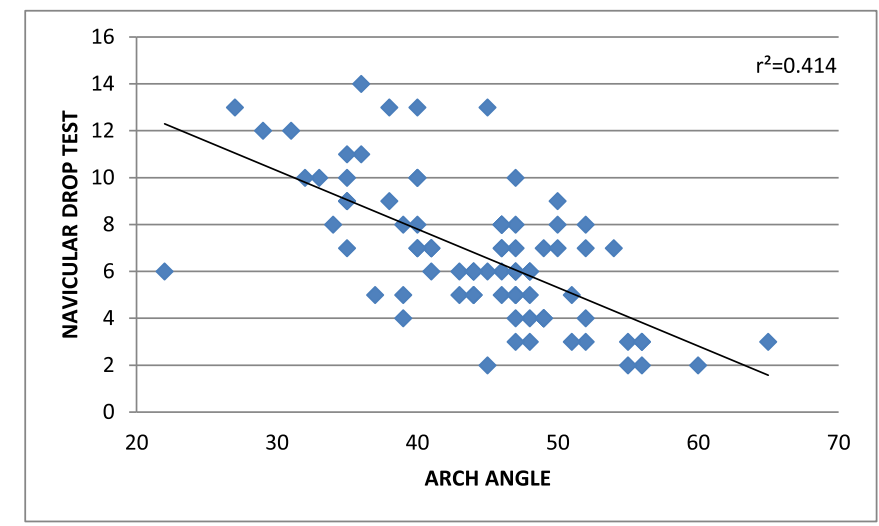

Fig 2. Correlation between arch angle and navicular drop test $(r=-0.643)$. The coefficient of determination $\left(r^{2}\right)$ is shown.

reported poor correlation between the AA, obtained by ink footprints, and navicular height $(r=0.39)$ in 115 participants. Shiang et $\mathrm{al}^{53}$ reported a fair correlation for the AA $(r=$ $0.457)$ and the CSI $(r=-0.483)$ and poor correlation for the SI $(r=-0.302)$ using digital footprints. Fair correlations were obtained by Queen et $\mathrm{al}^{17}$ for all parameters, ranging $r$ values from 0.469 to 0.517 . Levels of correlation increased using the normalized navicular height, with $r$ values ranging from 0.619 to 0.645 , which is similar to our findings.

The correlation between the NDT and the footprints parameters indicates that maybe other factors can affect footprint parameters. The footprints could be influenced by soft tissues. ${ }^{48,50}$ It was reported that the BMI was associated with the AI but not with the radiographic measures of the MLA $^{51}$ or the navicular height. ${ }^{54}$ The present research only included participants with BMI $<30$.

Regarding descriptive NDT values, it is commonly considered that normal MLA ranges from 5 to $9 \mathrm{~mm},{ }^{8,35,55}$ although Brody ${ }^{32}$ considered $15 \mathrm{~mm}$ as the limit of normal values. We obtained a mean value NDT of $6.7( \pm 2.9)$, which is within the range.

Nonstandardized values are commonly used for the AA, $\mathrm{CSI}$, and SI. With respect to the AA, $42^{\circ}$ is considered the lowest value for normal AA. ${ }^{56}$ Staheli $^{30}$ considered that, in adults, normal values of the SI ranged from 0.3 to 1 . The
CSI normal values ranged from $0.1 \%$ to $29.9 \%$. ${ }^{56}$ However, others values are used to categorize MLA, as presented by other authors. ${ }^{53,57,58}$ This could be a limitation to the categorization of the MLA using footprints parameters.

\section{Limitations}

First, this study was performed only with adults. This relationship should be evaluated in other samples, like children and older people. Second, this research has not included radiographic parameters. Radiographs are considered the gold standard for the evaluation of the MLA, ${ }^{28}$ and the use of them may be necessary to validate the NDT and the footprints parameters. Finally, our sample included all the spectrum of MLA height, and our results cannot be generalized for a specific foot type.

\section{CONCLUSION}

The correlations obtained between the NDT and the footprints parameters evaluated (the AA, SI, and CSI) were good. In addition, the NDT and footprints parameters, being reproducible, had an excellent intrarater and interrater reliability. The NDT is a reproducible, valid, and simple test for evaluating MLA height. It is commonly used in clinical 


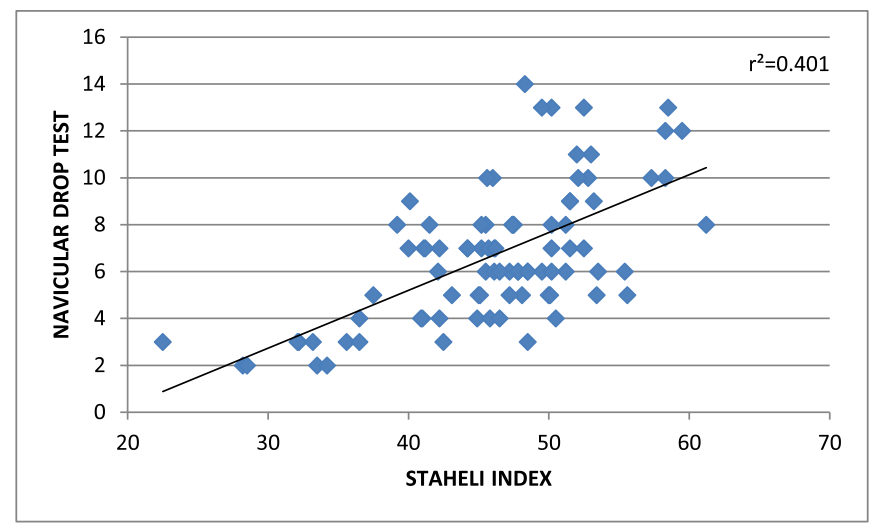

Fig 3. Correlation between Staheli index and navicular drop test $(r=0.633)$. The coefficient of determination $\left(r^{2}\right)$ is shown.

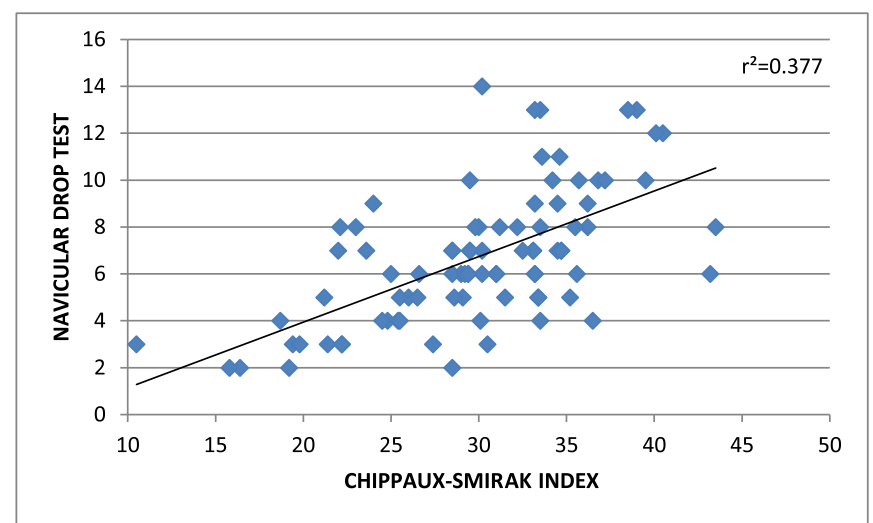

Fig 4. Correlation between Chippaux-Smirak index and navicular drop test $(r=0.614)$. The coefficient of determination $\left(r^{2}\right)$ is shown.

practice and research and has fewer disadvantages than using footprint parameters.

\section{Funding SOURCES AND CONFLICTS OF INTEREST}

No funding sources or conflicts of interest were reported for this study.

\section{CONTRIBUTORSHIP}

Concept development (provided idea for the research):

J.C.Z.-E., C.B.M.-C., J.A.M.-U., A.G.-C.

Design (planned the methods to generate the results):

J.C.Z.-E., C.B.M.-C., J.A.M.-U., A.G.-C.

Supervision (provided oversight, responsible for organization and implementation, writing of the manuscript):

J.C.Z.-E., C.B.M.-C., J.A.M.-U., A.G.-C.

Data collection/processing (responsible for experiments, patient management, organization, or reporting data): J.C.Z.-E., C.B.M.-C.
Analysis/interpretation (responsible for statistical analysis, evaluation, and presentation of the results): J.C.Z.-E., C.B.M.-C., J.A.M.-U., A.G.-C.

Literature search (performed the literature search): J.C.Z.-E., C.B.M.-C.

Writing (responsible for writing a substantive part of the manuscript): J.C.Z.-E., C.B.M.-C., J.A.M.-U., A.G.-C.

Critical review (revised manuscript for intellectual content, this does not relate to spelling and grammar checking): J.C.Z.-E., C.B.M.-C., J.A.M.-U., A.G.-C.

\section{Practical Applications}

- The navicular drop test and the footprint parameters had a high reliability.

- Good correlations were identified between the navicular drop test and footprint parameters. 


\section{REFERENCES}

1. Fiolkowski P, Brunt D, Bishop M, Woo R, Horodyski MB. Intrinsic pedal musculature support of the medial longitudinal arch: an electromyography study. J Foot Ankle Surg. 2003;42 (6):327-333.

2. Menz HB, Dufour AB, Riskowski JL, Hillstrom HJ, Hannan MT. Association of planus foot posture and pronated foot function with foot pain: the Framingham foot study. Arthritis Care Res. 2013;65(12):1991-1999.

3. Jonely H, Brismée JM, Sizer Jr PS, Cr James. Relationships between clinical measures of static foot posture and plantar pressure during static standing and walking. Clin Biomech. 2011;26(8):873-879.

4. Subotnick SI. The biomechanics of running: implications for the prevention of foot injuries. Sports Med. 1985;2(2):144-153.

5. Murley GS, Menz HB, Landorf KB. A protocol for classifying normal-and flatarched foot posture for research studies using clinical and radiographic measurements. J Foot Ankle Res. 2009;4(2):22.

6. Telfer S, Abbott M, Steultjens M, Rafferty D, Woodburn J. Dose-response effects of customised foot orthoses on lower limb muscle activity and plantar pressures in pronated foot type. Gait Posture. 2013;38(3):443-449.

7. Denyer JR, Hewitt NL, Mitchell AC. Foot structure and muscle reaction time to a simulated ankle sprain. J Athl Train. 2013;48(3):326-330.

8. Cote KP, Brunett ME, Gansneder BM, Shultz SJ. Effects of pronated and supinated foot postures on static and dynamic postural stability. J Athl Train. 2005;40(1):41-46.

9. Goffar SL, Reber RJ, Christiansen BC, et al. Dynamic plantar pressure changes during loaded gait. Phys Ther. 2013;93(9): 1175-1184.

10. Buldt AK. Foot posture is associated with kinematics of the foot during gait: a comparison of normal, planus and cavus feet. Gait Posture. 2015;42(1):42-48.

11. Franco A. Pes cavus and pes planus. Analyses and treatment. Phys Ther. 1987;67(5):688-694.

12. Tiberio D. The effect of excessive subtalar joint pronation on patellofemoral mechanics: a theoretical model. J Orthop Sports Phys Ther. 1987;9(4):160-165.

13. Nguyen AD, Boling MC, Levine B, Shultz SJ. Relationships between lower extremity alignment and the quadriceps angle. Clin J Sport Med. 2009;19(3):201-206.

14. Shultz SJ, Nguyen AD, Levine BJ. The relationship between lower extremity alignment characteristics and anterior knee joint laxity. Sports Health. 2009;1(1):54-60.

15. Shultz SJ, Dudley WN, Kong Y. Identifying multiplanar knee laxity profiles and associated physical characteristics. $J$ Athl Train. 2012;47(2):159-169.

16. Root ML, Orient WP, Weed JH. Normal and Abnormal Function of the Foot. Los Angeles, CA: Clinical Biomechanics Corporation; 1997.

17. Queen RB, Mall NA, Hardaker WM, Nunley II JA. Describing the medial longitudinal arch using footprint indices and a clinical grading system. Foot Ankle Int. 2007;28(4):456-462.

18. Sugathan HK, Sherlock DA. A modified Jones procedure for managing clawing of lesser toes in pes cavus: long-term follow-up in 8 patients. J Foot Ankle Surg. 2009;48(6): 637-641.

19. Williams III DS, McClay IS, Hamill J. Arch structure and injury patterns in runners. Clin Biomech. 2001;16(4):341-347.

20. Moen MH, Bongers T, Bakker EW, et al. Risk factors and prognostic indicators for medial tibial stress syndrome. Scand J Med Sci Sports. 2012;22(1):34-39.
21. Newman P, Witchalls J, Waddington G, Adams R. Risk factors associated with medial tibial stress syndrome in runners: a systematic review and meta-analysis. Open Access J Sports Med. 2013;4:229-241.

22. Reilly K, Barker K, Shamley D, Newman M, Oskrochi GR, Sandall S. The role of foot and ankle assessment of patients with lower limb osteoarthritis. Physiotherapy. 2009;95(3): 164-169.

23. Barton CJ, Bonanno D, Levinger P, Menz HB. Foot and ankle characteristics in patellofemoral pain syndrome: a case control and reliability study. J Orthop Sports Phys Ther. 2010;40(5): 286-296.

24. Hertel J, Dorfman JH, Braham RA. Lower extremity malalignments and anterior cruciate ligament injury history. J Sports Sci Med. 2004;3(4):220-225.

25. Loudon JK, Jenkins W, Loudon KL. The relationship between static posture and ACL injury in female athletes. J Orthop Sports Phys Ther. 1996;24(2):91-97.

26. Xiong S, Goonetilleke RS, Witana CP, Weerasinghe TW, Au EY. Foot arch characterization: a review, a new metric, and a comparison. J Am Podiatr Med Assoc. 2010;100(1):14-24.

27. Cowan DN, Robinson JR, Jones BH, Polly Jr DW, Berrey $\mathrm{BH}$. Consistency of visual assessments of arch height among clinicians. Foot Ankle Int. 1994;15(4):213-217.

28. Razeghi M, Batt ME. Foot type classification: a critical review of current methods. Gait Posture. 2002;15(3):282-291.

29. Cavanagh PR, Rodgers MM. The arch index: a useful measure from footprints. J Biomech. 1987;20(5):547-551.

30. Staheli LT, Chew DE, Corbett M. The longitudinal arch. A survey of eight hundred and eighty-two feet in normal children and adults. J Bone Joint Surg Am. 1987;69(3):426-428.

31. Urry SR, Wearing SC. A comparison of footprint indexes calculated from ink and electronic footprints. J Am Podiatr Med Assoc. 2001;91(4):203-209.

32. Brody D. Techniques in the evaluation and treatment of the injured runner. Orthop Clin North Am. 1982;13(3):542-558.

33. Shultz SJ, Carcia CR, Gasnneder BM, Perrin DH. The independent and interactive effects of navicular drop and quadriceps angle on neuromuscular responses to a weightbearing perturbation. J Athl Train. 2006;41(3):251-259.

34. Billis E, Katsakori E, Kapodistrias C, Kapreli E. Assessment of foot posture: correlation between different clinical techniques. Foot. 2007;17(2):65-72.

35. Nakhaee Z, Rahimi A, Abaee M, Rezasoltani A, Kalantari KK. The relationship between the height of the medial longitudinal arch (MLA) and the ankle and knee injuries in professional runners. Foot (Edin). 2008;18(2):84-90.

36. Hoffman M, Schrader J, Applegate T, Koceja D. Unilateral postural control of the functionally dominant and nondominant extremities of healthy subjects. J Athl Train. 1998;33(4):319-322.

37. Fleiss J. The Design and Analysis of Clinical Experiments. New York, NY: John Wiley \& Sons; 1999.

38. Qiao J, Xu L, Zhu Z, et al. Inter and intraobserver reliability assessment of the axial trunk rotation: manual versus smartphone-aided measurements tools. BMC Musculoskelet Disord. 2014;11(15):343.

39. Allen MK, Glasoe WM. Metrecom measurement of navicular drop in subjects with anterior cruciate ligament injury. $J$ Athl Train. 2000;35(4):403-406.

40. Mueller MU, Host JV, Norton BJ. Navicular drop as a composite measure of excessive pronation. J Am Podiatr Med Assoc. 1998;83(4):198-202.

41. Shrader JA, Popovich Jr JM, Gracey GC, Danoff JV. Navicular drop measurement in people with rheumatoid arthritis: interrater and intrarater reliability. Phys Ther. 2005; 85(7):656-664. 
42. Shultz SJ, Nguyen AD, Windley TC, Kulas AS, Botic TL, Beynnond $\mathrm{BD}$. Intratester and intertester reliability of clinical measures of lower extremity anatomic characteristics: implications for multicenter studies. Clin J Sport Med. 2006;16(2): 155-161.

43. Picciano AM, Rowlands MS, Worrell T. Reliability of open and closed kinetic chain subtalar joint neutral positions and navicular drop test. J Orthop Sports Phys Ther. 1993;18(4): 553-558.

44. Levinger P, Menz HB, Fottohabadi MR, Feller JA, Bartlett JR, Bergman NR. Foot posture in people with medial compartment knee osteoarthritis. J Foot Ankle Res. 2010;3:29.

45. McPoil TG, Cornwall MW, Medoff L, Vicenzino B, Forsberg K, Hilz D. Arch height change during sit-to-stand: an alternative for the navicular drop test. J Foot Ankle Res. 2008;1(1):3.

46. Vinicombre A, Raspovic A, Menz HB. Reliability of navicular displacement measurement as a clinical indicator of foot posture. J Am Podiatr Med Assoc. 2001;91(5):262-268.

47. Evans AM, Copper AW, Scharfbillig RW, Scutter SD, Williams MT. Reliability of the foot posture index and traditional measures of foot position. J Am Podiatr Med Assoc. 2003;93(3):203-213.

48. Cobey JC, Sella E. Standardizing methods of measurement of foot shape by including the effects of subtalar rotation. Foot Ankle. 1981;2(1):30-36.

49. Papuga MO, Burke R. The reliability of the associate platinum digital foot scanner in measuring previously developed footprint characteristics: a technical note. $J$ Manipulative Physiol Ther. 2011;34(2):114-118.

50. Wearing SC, Grigg NL, Lau HC, Smeathers JE. Footprintbases estimates of arch structure are confounded by body composition in adults. J Orthop Res. 2012;30(8):1351-1354.

51. Wearing SC, Hills AP, Byrne NM, Henning EM, McDonald M. The arch index: a measure of flat or fat feet? Foot Ankle Int. 2004;25(8):575-581.

52. Hawes MR, Nachbauer W, Sovak D, Nigg BM. Footprint parameters as a measure of arch height. Foot Ankle. 1992;13 (1):22-26.

53. Shiang TY, Lee SH, Lee SJ, Chu WC. Evaluating different footprint parameters as a predictor of arch height. IEEE Eng Med Biol Mag. 1998;17(6):62-66.

54. Gilmour JC, Burns Y. The measurement of the medial longitudinal arch in children. Foot Ankle Int. 2001;22(6):493-498.

55. Hargrave MD, Carcia CR, Gansneder BM, Shultz SJ. Subtalar pronation does not influence impact forces or rate of loading during a single-leg landing. J Athl Train. 2003;38(1):18-23.

56. Forriol F, Pascual J. Footprint analysis between three and seventeen years of age. Foot Ankle. 1990;11(2):101-104.

57. Gross KD, Felson DT, Niu J, et al. Association of flat feet with knee pain and cartilage damage in older adults. Arthritis Care Res. 2011;63(7):937-944.

58. Medi-Dan O, Gadi K, Zeev A, et al. The medial longitudinal arch as a possible risk factor for ankle sprains: a prospective study in 83 female infantry recruits. Foot Ankle Int. 2005;26 (2):180-183. 